\title{
Development of physical competence through motor skill acquisition for children and youth with disabilities: Parental perceptions
}

\section{BACKGROUND}

Parents are integral social agents in children's physical activity choices and involvement providing direct (feedback) and indirect (providing opportunities) competence information as well as multiple levels of support for activity engagement. Research is scant on parent perceptions and/or expectations specific to physical competencies and activity experiences among children with disabilities. The objective of this study was to capture parent perceptions of their child's physical competencies and physical activity experiences and any changes in perceptions as their child navigated learning cycling skills.

\section{PARTICIPANTS AND PROCEDURE}

Parents/guardians who had children enrolled in an adapted cycling camp participated in the pre- and post-focus group discussions $(N=14)$. Children's disabilities were developmental delay, Down syndrome, and autism spectrum disorder. Questions focused on parent perceptions about their child's physical activity experiences and thoughts and feelings about those experiences.

\section{RESULTS}

Main themes emerged from pre- and post-camp sessions. Pre-camp themes highlighted the child's past physical activity involvement (ex. barriers, opportunities). Incentives and motivations to participation and diminished perceptions of their child's abilities were the other main themes. Post-camp themes revealed child's reactions to the camp experience, effective pedagogy, benefits for learning to cycle and parent perceptions for child's success.

\section{CONCLUSIONS}

Introducing children with disabilities to physical activities that are both challenging and provide successful experiences contribute positively to parents' perceptions and expectations for activity. Parents see the benefits of effective pedagogy for learning physical skills, importance of adapted equipment in skill acquisition, competence, and confidence. Parents can be hopeful in future physical activity choices and opportunities for their children.

\section{KEY WORDS}

parents; Down syndrome; autism spectrum disorders; developmental disability; motor skills

ORganizations - 1: Ball State University, Muncie, IN, USA · 2: Southern Illinois University Edwardsville, Edwardsville, IL, USA

Authors' Contribution - A: Study design - B: Data collection - C: Statistical analysis - D: Data interpretation .

E: Manuscript preparation · F: Literature search · G: Funds collection

CORRESPONDING AUTHOR - Prof. Kimberly Sue Hurley, Ball State University, 2000 W University Avenue, Muncie, IN 47306,

USA, e-mail: kshurley@bsu.edu

TO CITE THIS ARTICLE - Hurley, K. S., \& Burt, T. L. (2015). Development of physical competence through motor skill

acquisition for children and youth with disabilities: Parental perceptions. Health Psychology Report, 3(1), 1-12.

DOI: $10.5114 /$ hpr.2015.47623 
Where little is expected, little is achievedparent of a child with autism

\section{BACKGROUND}

The development of physical abilities, specifically motor skills, is complex and varied, often influenced by a variety of genetic and contextual factors. Motor skill development is critical for multiple quality of life dimensions (Piek, Dawson, Smith, \& Gasson, 2008) and has been strongly linked with advanced movement skills and physical activity (Clark \& Metcalfe, 2002), intellectual and academic achievement (Dwyer, Sallis, Blizzard, Lazarus, \& Dean, 2001) and physical health parameters (Logan \& Getchell, 2010; Logan, Scrabis-Fletcher, Modlesky, \& Getchell, 2011). Motor development benchmarks can be helpful in identifying dramatic differences or delays in the emergence of motor patterns and skills. This is especially relevant as approximately one in six children in the United States is born with some developmental delay or disability (Boyle et al., 2011).

Disability can impact physical, intellectual, and social experiences and growth as individuals with disabilities often have less access to their communities and decreased opportunities for social interaction (Barnes, 1996). Much debate exists on how disability (physical, intellectual, sensory) impacts the development of motor skills and how intellectual development and motor development are linked. Regardless of the theoretical perspective on motor skill development such as Piaget's emphasis on motor activity as a prerequisite to cognitive development (Mandler, 1992) or Thelen's (as cited in Thelen \& Ulrich, 1991) emphasis on the importance of multiple factors such as motivation, movement, posture, balance along with neurological maturation, challenges for acquiring motor skills that will facilitate independence and integration into life activities is greater for youth with disabilities.

It is common knowledge that children with intellectual disability (ID), Down syndrome (DS), and autism spectrum disorder (ASD) tend to be less physically active and at an increased risk for associated health problems than children without disability (Esposito, MacDonald, Hornyak, \& Ulrich, 2012). Children with ID tend to score lower on motor performance tests involving eye/hand coordination, balance, and body coordination than children without ID and as motor task complexity increases, the balance and coordination deficits impede learning dramatically (Eichstaedt, Wang, Polacek, \& Dohrmann, 1991; Wade, Newell, \& Wallace, 1978). Specific research with children with DS has also supported the challenges in motor proficiencies and motor skills that may impact engagement in independent, life activities. Down syndrome is characterized by delays in motor development and movement patterns that lack fluency (Jobling, 1999). Poor postural stability and balance, strength deficits, slow reaction times may all impact movement competencies among children with DS (Jobling \& Mon-Williams, 2000; Parker, Monsoon, \& Larkin, 1993; Webber, Virji-Babul, Edwards, \& Lesperance, 2004). Additionally, MacDonald, Jaszewski, Esposito, and Ulrich (2011) found that social skills (e.g., independence, positive emotions, successful coping strategies) can be practiced and enhanced along with motor skill practice and development (i.e., two-wheel cycling skill acquisition) among youth with ASD.

Herein lies the dilemma; learning and engaging in physical skills and activities can improve many of the developmental conditions that are characteristic among children with DS yet the process of learning necessary physical skills can be frustrating and resource consuming. Physical therapy assists in basic motor skill development, flexibility and balance but more complex loco-motor skills that are necessary for physical activity and sport skills engagement are often times not priority. Additionally, primary care givers (parents, grandparents, guardians) typically do not have the expertise or personal resources (i.e., time, money, coping) to help refine physical activity skills that require sequencing, timing, and coordination of several motor patterns simultaneously, along with guided practice (e.g., cycling, swimming). These lack of resources serve as stressors for family members of children with DS as they wrestle with mastery, satisfaction, and confidence in caregiving (Guralnick, 2000). Virji-Babul, Eichman, and Duffield (2004) found that families of children with DS often receive messages from health professionals that reflect attitudes and expectations for active lifestyles that are unreasonably negative and lower than necessary. These inaccurate prognoses may undermine parents' and guardians' efforts to seek and provide optimal activity opportunities (social and physical) for their children with DS. Thus a child with DS may be disadvantaged for learning and engagement in lifelong physical activities from both internal (organic) and external (environmental) conditions.

Child development research with school-aged children diagnosed with ASD has consistently found subtle to significant delays and disorders in overall motor development. Upwards of $70 \%$ of children with ASD experience motor development delays (Berkeley, Zittel, Pitney, \& Nichols, 2001; Manjiviona \& Prior, 1995; Mari, Castiello, Marks, Marraffa, \& Prior, 2003; Mayes \& Calhoun, 2003). This disability is complex involving multiple neurosensory challenges. However the most pervasive deficits are those in receptive and expressive communication and socialization as well as evidence of repetitive or restricted behaviors and interests (American Psychiatric Association, 2000; Horovitz \& Matson, 2010; Matson, Dempsey, 
\& Fodstad, 2009). Receptive and expressive communication are important components in the learning process thus delays in motor skill acquisition and abilities for complex motor patterns are marked among children with ASD. These delays combined with socialization deficits dramatically limit engagement in physical activities.

Learning delays and deficits in the development of motor skills along with less-than-adequate physical activity patterns may contribute to overweight and obesity levels among children with ASD (Curtin, Anderson, Must, \& Bandini, 2010) putting them at risk for health challenges in both youth and adulthood. Clearly quality of life indices for individuals with ASD are dramatically impacted by communication and learning challenges, social awkwardness, and social isolation. Facilitating the development of motor skills and physical competencies can improve physical and social health parameters for children and adults with ASD.

\section{PHYSICAL COMPETENCE}

Physical competencies or lack of, are overtly displayed when engaging in physical activities. Information about physical competence is often gleaned from evaluations from others or self-reflection. This information in turn, contributes to individual perceptions about physical abilities and physical self-worth, as well as global self-esteem (Fox, 1997; Harter, 1987). Conversely, individuals' perceptions of competence can influence behaviors (i.e. activity choices, continued participation in the chosen activity), intrinsic motivation for activity, affective responses (i.e. enjoyment, anxiety, pride, shame), and perhaps preferences for various sources of competence information about abilities (McKiddie \& Maynard, 1997; Weiss \& Ebbeck, 1996). Logan et al. (2014) reviewed youth research examining the link between fundamental motor skill (FMS) proficiency and physical activity levels. Results from 25 studies reveal "that across all ages, the most physically active children are also the most competent in FMS”. These findings support the significance of the relationship between motor skill competency and physical activity levels. Self-perceptions of competence also impact thoughts and behaviors toward activity engagement.

From a cognitive developmental perspective, very young individuals tend to have inaccurate self-perceptions of ability believing that trying hard (effort) equals being good at a particular skill (Nicholls, 1978). Fry and Duda (1997) reinforced this phenomenon among children in both physical and academic contexts that are often referred to as achievement domains. Research on children and achievement motivation shows that challenging tasks may result in children responding with helpless behaviors (low motivation, disengagement) or mastery-oriented behaviors (self-instruction, self-motivation). Failure feedback produces behavioral and cognitive responses that contribute to off-task behavior, negative affect and children may develop inaccurate beliefs of poor future performance or low ability across many tasks (Diener \& Dweck, 1978, 1980).

Young individuals with disabilities (e.g. ASD, DS) may not have the ability to accurately gauge their physical competencies and/or abilities therefore limiting physical activity pursuits. In addition, children with mild to moderate physical disabilities typically experience physical challenges, frustrations, and failures when engaging in non-adapted physical activities (King, Law, Petrenchik, \& Hurley, 2013; Liberman, Ratzon, \& Bart, 2013; Murphy \& Carbone, 2008). Conversely, Sherrill (2004) emphasizes that individuals with disabilities who have positive, successful physical activity experiences will have improved physical self-competence and self-worth. Diener and Dweck (1978) highlight the power of mastery or success beliefs for children in that they will stay on task, more accurately recall past performances, maintain positive self-evaluations and have higher motivations for activity engagement. It is evident that engaging in physical activity is very important for individuals with disabilities from a physical (Lotan, Henderson, \& Merrick, 2006) and psychological health perspective (Sherrill, 2004).

\section{PARENT PERCEPTIONS}

Parents/Guardians are typically integral social agents in children's physical activity choices and involvement (McKiddie \& Maynard, 1997; Payne \& Isaacs, 2005) and are a major source of competence information for children. According to Harter (1987) parents/guardians are influential as contributors to children's self-esteem, affect, and motivations in achievement domains such as physical activity pursuits. Unfortunately, very little research has revealed parents' perceptions and/or expectations about their child's physical abilities and competence and engagement in physical activities, especially among parents of children with disabilities.

Many parents of children with disabilities applaud the inclusion of physical education (P.E.) as a part of the general education curriculum highlighted in Public Law 108-446, Individuals with Disabilities Education Improvement Act of 2004 (IDEIA). Parents/ guardians desire increased exposure to services such as physical activities that include and can improve social interactions. Regrettably, parents and caregivers of children with disabilities report challenges and stressors related to behavior management and inadequate support or training for physical activity skills that may need additional practice outside the P.E.
Development of physical competence 
Kimberly Sue Hurley,

Tammy Lee Burt classroom (Allen, Hawkins, \& Cooper, 2006; Hastings, Thomas, \& Delwiche, 2002).

The objective of this study was to interview parents/guardians of children with disabilities in order to glean information regarding perceptions of their children's physical competence, expectations for learning how to ride a bike, and any changing perceptions/expectations based upon their children's learning experiences at the iCan Shine (iCS) Inc. bike camp for individuals with disabilities. iCan Shine is a national nonprofit organization that has demonstrated exceptional outcomes with its adapted cycling program.

Over the past seven years since its inception in 2007 , iCS in cooperation with local organizations has facilitated the acquisition of conventional cycling skills for approximately 20,000 people with disabilities. iCan Shine reports an $80 \%$ success rate in their adapted cycling program ("Who we are", n.d.-a). Participants at an iCS bike camp attend five consecutive days for 75 minutes per day. Camp participants are introduced to cycling on adapted roller bikes with the goal of progressing to a conventional two-wheel bicycle by week's end. Refer to Ulrich, Burghardt, Lloyd, Tiernan, and Hornyak (2011) for a detailed account of the training progression. The adapted roller bikes used by the iCan Shine organization were custom designed and manufactured by Dr. Richard Klein of Rainbow Trainers Inc. (Fiske, 2005; "Who we are", n.d.-b). Several research studies have been developed as a result of the widespread use of the adapted roller bikes through the iCS program (Burt, 2002; Ulrich et al., 2011; MacDonald, Esposito, Hauck, Jeong, \& Hornyak, 2012; Hauck, Jeong, Esposito, MacDonald, \& Ulrich, 2014; Pitchford, Hauck, Ketcheson, Reynolds, \& Ulrich, 2014).

The premise of this research is to gain understanding of parents' expectations for their children's success in challenging physical pursuits. Ultimately results could lead to a broad scope of educational information that would be beneficial to parents/guardians of children with disabilities, physical educators, and community programmers who teach students with a vast array of abilities, preferences, and experiences.

\section{PARTICIPANTS AND PROCEDURE}

Upon university institutional review board (IRB) approval, parents were recruited during the camp registration process via mail and in person on day one of the iCS camp. Participants included 14 mothers, fathers, and/or guardians of children with disabilities $(N=14)$. Participants' age range was $32-57$ years $(M=47.00$ yrs., $S D=7.64$ yrs.). The majority of participants were Caucasian $(n=12)$ and two were of East Indian descent. Children's ages ranged from 7-21 years and the list of disabilities included DS, ASD, ID, and developmental delay (DD).

Two parent focus groups ( $n=6$ and $n=8$, respectively) were formed (divided based upon their child's camp session) and participants were instructed on the use of audio recording procedures, how the recordings would be used, and how the audio recordings would be secured. The focus groups were conducted in a quiet room separate from the gymnasium using a semi-structured question/discussion format ( 15 questions and probes, 30-45 minutes sessions) during their child's first (day one) and final (day five) iCS session. All participants were informed of their confidentiality, anonymity and right to withdraw from the study at any time without negative consequences for them or their children at the camp.

The focus group questions were based upon Harter's (1990) multidimensional model of perceived competence and self worth. Weiss and Ebbeck (1996) customized Harter's model of global self worth specific to the physical activity domain. This adaptation provided the framework for development of focus group questions. Questions were assessed for validity and reliability via discussion sessions with parents, pedagogy and psychology experts, and certified adapted physical education (CAPE) specialists. Questions and probes were discussed and edited until the final set of items was obtained through a consensus of the recruited specialists.

Session 1 (pre): Questions pertained to their child's past physical activity (PA) experiences, parents' perceptions of their child's physical competence, and parents' expectations specific to bike camp outcomes.

Session 2 (post): Questions focused on parents' current perceptions of their child's physical competence, accuracy of parental expectations, and thoughts about future physical activity pursuits.

Audio recordings of the focus group sessions were then transcribed verbatim by primary researchers and graduate assistants trained in transcription techniques. Triangulation was utilized for examining audio transcripts in order to identify common themes and provide evidence for credibility and validity of findings. This process affords examination of the interview data from multiple standpoints in order to crosscheck the data for both richness of detail and regularities of themes (Cohen \& Manion, 1986; O’Donoghue \& Punch, 2003). Three kinesiology professionals (pedagogy, adapted physical activity/education, and sport/exercise psychology) analyzed the transcripts and collaborated on themes that appeared prevalent.

\section{RESULTS}

Approximately $60 \%$ of the participants' children learned to ride a conventional two wheel bicycle with 
minimal or no assistance by the final day of camp (day five). The remaining $40 \%$ made significant progress toward the goal of independent riding. Additionally, as per the iCS camp protocol, parents/guardians/ siblings received training in spotting to continue the learning experience at home. All parents/guardians contributed in providing important details about the week-long experience for both their children and their family. A total of 155 specific parent comments $(N=155)$ were successfully isolated from the transcripts for use in identifying themes. Pseudonyms are utilized for all names that were disclosed during the focus group discussions. No further identifying information was secured from parents regarding their children during the focus group interviews thus no specific age or gender information (aside from pseudonym gender-matched names) is available to link a child to any specific parent comment.

Three main themes emerged from a total of 11 PreCamp subthemes identified from parent comments ( $n=78$; see Table 1 ). Each main theme is accompanied by examples from study participants.

\section{Physical activity involvement}

"Yeah, there's nothing around in our area except for the Special Olympics I mean I have searched and searched and searched, written letters, and emailed people and there is nothing."

"I know when I wanted my son to go to regular swimming lessons I didn't think he could participate in the regular class, because he's a little flighty and so the $\mathrm{Y}$ only offered us private lessons and that was much more expensive... but I think the lack of availability for special needs kids."

"I think being misunderstood is a big barrier..."

"Just lack of knowledge of other people..."

"...if you find someone who has doubts right from the get-go you know and you don't progress..."

"We swim together as a family, and Nicholas and I will take walks together occasionally..."

"We go to Aikido every Saturday and Sunday morning and I assist in the class so I am there with him."

"We don't have anything structured, just play around the yard..."

"I hear there is a lot in the St. Louis area... on the Illinois side we're lacking. There is a Challenger baseball league."

"They've got a soccer league, yeah, but that's so far to drive for me."

"We used to do therapeutic riding too..."

"I'd sign him up for little league, but he really isn't interested. He'd rather swing on the swings or play with the remote control car."

"My son swims in the Special Olympics and regular P.E. in school, so he's not very good at regular P.E. but he does participate."

2. Incentives to participation in physical activities "We celebrate."
Table 1

Pre-camp emergent themes and percentages of total comments

\begin{tabular}{ll}
\hline Main themes $^{\mathrm{a}}$ and subthemes & \\
\hline Physical activity involvement $^{\mathrm{a}}$ & $\%$ \\
Barriers/frustrations to participation $^{\mathrm{b}}$ & \\
Family member preferences $^{\mathrm{b}}$ & \\
Inclusive physical activity experience $^{\mathrm{b}}$ & \\
Current physical activity $^{\mathrm{b}}$
\end{tabular}

Incentives to participation in physical activity $^{\mathrm{a}}$

Feedback following success/failure in physical activity

Reactions to success/failure in physical activity ${ }^{\mathrm{b}}$

Motivation to participate in physical activity $^{b}$

Value of physical activity

Pedagogy at adapted bike camp ${ }^{\text {b }}$

Parental perceptions regarding child's motor skills ${ }^{\mathrm{a}}$

Perceived competence ${ }^{b}$

Expectations $^{\mathrm{b}}$

Total comments $(n=78)$

"High fives."

“...he'll say 'good job' to himself."

"...when Dmitri has a belt test, and pass we go out to dinner for whatever his favorite food is."

"We always have to go to McDonalds."

"Well, you know, 'It's okay,' or 'We'll try again' or you know 'We'll do something else'."

"...or point out the positives..."

"Yeah, or make light of it, so they don't just focus on the negative."

"They asked her to do something and she was doing it. She had the full attention of two adults and she was just beaming."

"My son really understands the importance of a gold medal instead of a silver medal..."

"I'm not good at that, I'm good at... something else, so, I should do what I'm good at and not what I'm not good at."

"Yeah, and I would say resistance to do it again... just kind of human nature."

"...I think that sometimes he will go out and be physical like on a swing or on a scooter board cause I think he realizes even though he can't verbalize it that that calms him down."

"Fitting in." 
"Yeah, I think he want to play with the other kids and that's the big motive."

"Praise."

"Well, the motive is the reward of the medal..."

"I think it's very important not only for kids but for adults. You know, just health wise..."

"...it helps with their self-esteem. They feel like, like they've done something."

"Well, it looks like they have the kids on the bikes right away. That's good, don't let them sit around and get anxious."

Kimberly Sue Hurley, Tammy Lee Burt

3. Parental perceptions regarding child's motor skills

"I don't even know if he's ready now but" (chuck- le) "I'm ready to buy him a bike" (laughter).

"Well, I have to see if he's even interested like in this, because" (laughter) "I have pressured him into stuff that he doesn't want to have anything to do with."

"I'm hoping he goes to a bike because he loves his battery operated four-wheeler... and he doesn't

Table 2

Post-camp emergent themes and percentages of total comments

\begin{tabular}{|c|c|}
\hline Main themes ${ }^{a}$ and subthemes ${ }^{b}$ & $\%$ \\
\hline $\begin{array}{l}\text { Child's reactions to adapted bike camp } \\
\text { experience }{ }^{\mathrm{a}}\end{array}$ & 40 \\
\hline \multicolumn{2}{|l|}{ Increased confidence ${ }^{b}$} \\
\hline \multicolumn{2}{|l|}{ Positive affect ${ }^{b}$} \\
\hline \multicolumn{2}{|l|}{ Increased social interaction ${ }^{b}$} \\
\hline \multicolumn{2}{|l|}{ Changes in attitude ${ }^{b}$} \\
\hline \multicolumn{2}{|l|}{ Complaints ${ }^{\mathrm{b}}$} \\
\hline \multicolumn{2}{|l|}{ Increased independence ${ }^{b}$} \\
\hline Pedagogy at adapted bike camp ${ }^{a}$ & 24 \\
\hline \multicolumn{2}{|l|}{ Teachers' expertise ${ }^{b}$} \\
\hline \multicolumn{2}{|l|}{ Environment $^{\mathrm{b}}$} \\
\hline \multicolumn{2}{|l|}{ Repetition ${ }^{\mathrm{b}}$} \\
\hline \multicolumn{2}{|l|}{ Skill presentation ${ }^{\mathrm{b}}$} \\
\hline Benefits of cycling acquisition ${ }^{a}$ & 18 \\
\hline \multicolumn{2}{|l|}{ IEP goals in physical education ${ }^{b}$} \\
\hline \multicolumn{2}{|l|}{ Increased social opportunities ${ }^{b}$} \\
\hline \multicolumn{2}{|l|}{ Increased confidence ${ }^{b}$} \\
\hline $\begin{array}{l}\text { Parental expectations of cycling skill } \\
\text { acquisition }\end{array}$ & 18 \\
\hline \multicolumn{2}{|l|}{ Low expectations ${ }^{b}$} \\
\hline \multicolumn{2}{|l|}{ Child would learn to ride ${ }^{b}$} \\
\hline \multicolumn{2}{|l|}{ Set higher goals for success ${ }^{b}$} \\
\hline Total comments $(n=77)$ & 100 \\
\hline
\end{tabular}

have to use his legs, that's where he needs to build his strength is his lower body."

"...then they bump him up to little league or pee wee and we're afraid he'd get hurt you know, because he'd be too busy goofing around than paying attention..."

"I've heard my daughter say, 'I did a great job', but that might be more effort or compliance, I don't know..."

“...and my son will say after playing basketball with the kids, 'I don't like basketball, I don't like it when they throw the ball at me, it might hit me', he's a little fearful of... contact."

"I guess with my son in swimming you know we can see progress because when he first started they would put bubbles on him and he swims across the pool with three bubbles and then we went down to two bubbles, and then one, then he was just wearing the strap around his waist and swimming on his own, so you could see that. And now in swimming, you know, they do it by times and he's getting faster and he looks better and you can visually see it, his progress."

Post-Camp sessions were emotionally rich as parents/guardians shared feelings of joy for their child's accomplishments $(n=77)$. Four main themes emerged post-camp from a total of 17 subthemes (see Table 2). One theme reflected parental direct observation of children throughout the week. Three themes pertained to parental thoughts centered on the camp experience. Each theme is introduced below accompanied by quotes from participants.

1. Child's reaction to adapted bike camp experience

"June signed up for summer school at Meramec to take another gym class so now she's taking water aerobics, she's never taken water aerobics before so she did say today, 'I think I can get an A in that class' she never says that, but anyway, so I think that's pretty confident myself for anything dealing with physical activity with her."

"Well, Lamar's language is very limited, um, but his consistent praise was 'I did it' and to call everybody in the family to tell them, 'I did it'."

"Rudy was saying his prayers and it wasn't anything from me ya know, he just said 'oh thank you for letting me have this great day, it was one of the best days of my life and I got to ride a bicycle by myself'... he's just so happy that he was by himself.'

"My granddaughter's usually the one who sits in the corner by herself, she's out there she's hugging the instructors and stuff, ya know, runs to them when she comes in the doors..."

"June just felt so positive and happy about the whole, this child is never happy about anything, you know, it's just amazing to me, who is that? Normally, I had never signed up for camps...she'll go the first day and she never wants to go back, so it was amazing when she wanted to come back the second day."

"...the first couple of days said her rear hurt..." 
"how cool he said", "once I learn it then I can go to my friends..."

\section{Pedagogy at adapted bike camp}

"...the difference is the depth of knowledge that surrounds her in this physical exercise experience so as soon as a barrier comes up there's a strategy to try... what you're doing is really what's helping (child's name) and making the experience completely different. If we were at a park and rec experience (snap) you're outta there... the difference was really there was... people with tons of experience you know great attitudes."

"...he loves to move, but you know, they need that more controlled... at least he does..."

"a child that has a disability... needs more time, needs more work... or needs more tries..."

"...I see here that he's learning on a really fast pace but I think it's because he's taught individually based on who he is and they're feeling him out and figuring out what motivates him, they're not treating my child the same way they're treating her child and they're giving him individual attention..."

\section{Benefits of cycling acquisition}

"...cycling is something the he can, we hope, do you know and that could help with weight management besides just being an activity that he could be equal to other children. Right now, he is never equal."

"Talk about functional daily living skills, if you're never going to drive, if you have access to a bike, you can go places."

"...they are just so excited together about what's going on and they're just feeding off of each other and it's so much fun to just watch how excited they are and how goofy they are with each other... just to watch them after class how they are just so giddy you can hardly get them out of here" (laughter).

"...this is a skill where they could work by themselves and develop strength and so much confidence... and it's right there, ya don't have to take them to the swimming pool ya know."

4. Parental expectations of cycling skill acquisition

"I think this has shown that they can do something that we thought they couldn't do so we should never say they couldn't or they can't, you know, because there may be a way for them to."

"I never know what to expect with him, so I try not to have any specific expectations."

"...our expectations were that she would learn how to ride a bike at the end of the week, that she would be competent in some way to do that, but we didn't realize that she would be like almost a different person..."

"...where little is expected little is achieved..."

\section{DISCUSSION}

Introducing children with disabilities to physical activities that are challenging and concurrently pro- viding multiple opportunities for success may have a positive impact on parents'/guardians' future expectations and physical activity choices for their children. Weiss and Ebbeck's (1996) proposed framework for children's competence motivation in activity emphasizes the importance of information gleaned from physical activity successes as well as information (verbal or non-verbal) from interactions with parents' and/or guardians' regarding physical competencies. These information sources contribute to positive or negative affect, self-esteem, and motivation for continued physical activity. Ulrich and colleagues found that parents of children with DS perceived that their children were less fearful and more motivated to try new physical activities after overcoming their fear and learning how to ride a bicycle (Ulrich et al., 2011).

Parents are wonderful advocates; many parents seek opportunities for their child, assist with planning and practice for their child, and experience their child's successes and failures. However, specific to physical development and activity engagements parents may not fully understand how important their role is. For instance, parents may be unaware of the type of physical competence information (e.g. positive, negative) they are projecting to their child with regard to his/her potential physical activity pursuits. A parent who provides positive regard for his/her child's physical abilities and efforts may ultimately stimulate the child to continue to pursue physically challenging activities while providing a buffer for negative failure feedback from unsuccessful efforts and outcomes in physical activities (Horn \& Harris, 1996). This phenomenon has distinct implications for children with disabilities, as they tend to be less active, physically and socially than their peers who are non-disabled, which puts them at greater risk for quality of life challenges.

Many parents or caregivers may not grasp the importance of their involvement in their child's physical activity experiences as children with developmental disabilities typically need more practice time and attempts to master skills and activities. Extended time for physical activities is rarely scheduled during the school day so the responsibility for additional practice lies with caregivers. Guralnick (2000) highlights how the family system that surrounds the child with DS is highly motivated to advocate and manage many of the child's needs but do fall short in roles related to "play partner, emotion regulator, and nurturer of self-identity and autonomy". Parents and guardians of children with disabilities seem to agree on the importance of physical and social opportunities in order to enhance their child's development but lack key skills for facilitating their child's success in activity pursuits (i.e., expert knowledge in motor development, patience and persistence in behavior management, successful pedagogy practices).
Development of physical competence 
Kimberly Sue Hurley,

Tammy Lee Burt
In the pre-camp sessions most parents were uncertain as to what to expect of their child's biking competence since none of the children had yet successfully acquired any cycling skills. Post-camp parent focus group sessions were filled with emotion and all parents were extremely positive about their child's biking experience. These findings align especially well with Weiss and Ebbeck's (1996) model as these parents/guardians clearly could provide a source of positive social regard toward their child's physical competency and in turn influence self-esteem, positive affect, and potentially motivation for activity. This outcome has premier importance.

Menear's (2007) results with parent focus groups revealed that parents recognize the significance of their child's involvement in physical activity for physical and mental health outcomes. The parents in Menear's study shared disappointment with some community programming (e.g., Special Olympics) that did not meet their child's physical and cognitive needs or did not provide adequate training and practice for skill development and acquisition. Multiple pre-camp comments from the parents/guardians in this study align with those from Menear's findings. Parents desire working strategies for facilitating their child's success outside of formal programming.

Developing and utilizing diverse and creative teaching strategies for children with disabilities can be critical in facilitating success for physical activity pursuits. The iCS camp in which the children participated is rather unique in its emphasis on immediate success followed by increasingly more challenging experiences that are presented in a step-by-step progression. It is imperative to match the ability of the child to the task at hand, whether the skill is bicycling, swimming, or tennis. Not only does this practice lead to successful skill acquisition (Burt, Porretta, \& Klein, 2007), but it can also have a positive effect on movement confidence (Griffin \& Keogh, 1982) and motivation (Harter, 1987).

Quality of life dimensions for individuals with disability (e.g., intellectual, sensory, physical) continue to emerge as vital research avenues. For instance, Rimmer and Yamaki's (2006) research review of the prevalence of obesity among individuals with ID highlights the need for physical activity intervention strategies. At post-camp discussions in this study a parent shared the possibility of cycling as a strategy for weight management for his/her child. The 2003-2008 National Health and Nutrition Examination Survey (NHANES) report obesity rates among children with disabilities are approximately $38 \%$ higher than children without disabilities (Centers for Disease Control [CDC], 2010). Further support for cycling's efficacy for weight management is provided by Ulrich et al. (2011) who found children with DS who learned the skill of bicycle riding spent signifi- cantly less time in sedentary activity and had lower body fat percentage 12 months after skill acquisition.

Another important post-camp theme focused on the effectiveness of pedagogy in the physical activity context. These findings are in alignment with Goodway, Wall and Getchell (2009) who stress how proficiency of FMS can be expedited via developmentally appropriate instruction and extensive opportunities for practice. These researchers suggest purposeful, developmental instruction that is direct and individualized with specific feedback and adequate equipment. The iCS camps are designed to provide this type of environment (pedagogy and context) and parents commented on their child's improved pace of learning because of individualized attention and instruction. One parent also commented on prompt, effective pedagogy strategies utilized by camp personnel that quickly helped his/her child overcome barriers to learning.

While creating an ideal learning environment through best pedagogical practices is necessary for some level of success, teaching strategies alone will not suffice. The progressive system of roller bikes is designed to meet the individual at the proper level of challenge thus introducing successful attempts from the start. Without the bicycle adaptations, it would be very difficult if not impossible to introduce the child to the "zone of proximal development" best suited for him/her to experience the success needed to encourage and advance their individual learning (Vygotsky, 1978). The combination of equipment design and expert pedagogy makes this program a success. Pedagogy strategies have to be in place to make the most of the available equipment. It is necessary for the children to (1) get on the bikes, and (2) stay on the bikes to receive adequate practice. Finally, is the knowledge of the teacher as to the readiness of the child to move to the next level of challenge.

Goodway et al. (2009) suggest that children with poor motor skill proficiency tend to disengage from activity, have poor self-perceptions of their physical abilities, and this phenomena becomes more pronounced as they age. These kids may drop out of physical activity completely. Parents in this study sounded hopeful in their child's future physical competence development and future activity choices and opportunities. Research in motor development consistently supports the progression of learning experiences that are varied and extensive in order to increase physical competence and increased motor competence contributing to "confident and competent movers” (Goodway et al., 2009).

How physical activity, specifically cycling, positively impacts several physical parameters is extremely important but psychosocial outcomes are influenced positively as well. Social development of children with ASD was positively influenced following acquisition of cycling skills (MacDonald et al., 
2011). Cycling provides increased transportation opportunities, socialization with peers, and can become a lifetime fitness/leisure outlet. Increased exposure to physical activities may lead to healthier lifestyle and improved physical self-worth and psychological self-esteem for children with disabilities. Parents in this study shared aspirations of independence and improved health for their children who successfully learned to ride.

Socialization through activity engagement is often one of the most valuable outcomes for individuals with disabilities. Goldstein, Kaczmerek, and English (2002) also stress the importance of social interactions for learning social skills and peer group norms that contribute to successful friendships for individuals with disabilities. Social barriers, specifically negative social attitudes towards individuals with disabilities, emerge consistently as contributors to non-participation in community recreation programs (Bedini, 2000; Tsai \& Fung, 2005). MacDonald et al. (2011) highlight the perfect recipe when individuals with disabilities are provided opportunities to learn motor skills and social skills in structured program settings that carry over into other life domains. Success in physical skills often reduces the gap between disability and ability. Multiple parents spoke at postcamp sessions about the possibility of their child being "less different now... from other kids" and more "equal to other children". The thoughts and feelings that parents shared about their children's successes were powerful reinforcements for providing future opportunities.

The pattern that emerged from this research is as follows: successful experience (not just outcome but also the daily riding process), positive affect (excitement, enjoyment), increased self-esteem and motivation as children expressed desire to continue the camp experience and future aspirations for engagement in other physical activities. This mirrors Harter's (1990) motivation model for self-perceptions in achievement domains. Although a limitation of this research was not directly assessing camp participants' perceptions, the parents/guardians provided rich detail of their child's responses to the physical activity experience.

Limitations to this research include the specificity of focus on perceptions of physical competence and exclusion of parent perceptions of social competence during their child's camp experience. Not all campers were successful riders but may have had successful social outcomes. Future research should include multiple competencies. Social competencies are critical to reducing barriers to inclusion for children and adults with disabilities (Bedini, 2000). Although some results highlighted social outcomes, the research questions did not probe into the nuances of any changes to children's social competence or confidence as a result of camp participation. Social confidence is an- other variable of interest in future research because children with disabilities often experience social exclusion either directly (environmental constraints) or indirectly (cannot share common experiences) in many physical activity pursuits. Activity programs and interventions that diminish any skill gaps between disabled and non-disabled children have great promise for focus on abilities and increased opportunities versus disabilities and limitations.

\section{CONCLUSIONS}

Ensuring availability of diverse and affordable physical activities (structured or unstructured) for children and adults with disabilities should be a priority at both the school and community level. Research on adults with DS has consistently supported significant health benefits resulting from lifelong community engagement in physical activity (Barnhart \& Connolly, 2007; Fujiura, Fitzsimons, Marks, \& Chicoine, 1997). These positive health outcomes among a population that is traditionally at risk for negative health parameters from childhood into adulthood should provide enough evidence for development and implementation of interventions and programming that enable individuals with DS to develop and maintain physical activity. Although further research is needed on lifelong activity engagement in individuals with other disabilities (e.g., ASD, ID), the trend for positive health outcomes is consistent among ALL populations.

National Standards for Physical Education (National Association for Sport and Physical Education [NASPE], 2004) supports the provision that all students have the opportunity to access and succeed in achieving the physical education standards. Children and adults with disabilities who experience successful physical activity and leisure pursuits can also serve as role models for other individuals with disabilities and their parents and/or caregivers. Inclusiveness in physical activities can be critical to breaking stereotypes that often accompany disability, thus implementing programs and curriculum that facilitate success is empowering for all individuals involved.

\section{RefERENCES}

Allen, D., Hawkins, S., \& Cooper, V. (2006). Parents' use of physical interventions in the management of their children's severe challenging behavior. Journal of Applied Research in Intellectual Disabilities, 19, 356-363. DOI: 10.1111/j.1468-3148.2006.00292.x

American Psychiatric Association (2000). Diagnostic and statistical manual of mental disorders ( $4^{\text {th }} \mathrm{ed}$., test rev.). Washington, DC: Author.
Development of physical competence 
Barnes, C. (1996). What next? Disability, the 1995 Disability Discrimination Act and the campaign for disabled peoples' rights. Skills, 55, 7-9.

Barnhart, R. C., \& Connolly, B. (2007). Aging and Down syndrome: Implications for physical therapy. Physical Therapy, 87, 1399-1406. DOI: 10.2522/ ptj.20060334

Bedini, L. A. (2000). Just sit down so we can talk: Perceived stigma and community recreation pursuits of people with disabilities. Therapeutic Recreation Journal, 34, 55-68.
Kimberly Sue Hurley, Tammy Lee Burt
Berkeley, S. L., Zittel, L. L., Pitney, L. V., \& Nichols, S. E. (2001). Locomotor and object control skills of children diagnosed with autism. Adapted Physical Activity Quarterly, 18, 405-416.

Boyle, C. A., Boulet, S., Schieve, L. A., Cohen, R. A., Blumberg, S. J., Yeargin-Allsopp, M., Visser, S., \& Kogan, M. D. (2011). Trends in the prevalence of developmental disabilities in US children, 19972008. Pediatrics, 127, 1034-1042. DOI: 10.1542/ peds.2010-2989.

Burt, T. L. (2002). Effects of adapted bicycles plus feedback on the acquisition, maintenance, and generalization of conventional cycling skills for children with mild mental retardation (Doctoral dissertation). Retrieved from ProQuest, UMI Dissertations Publishing (3049000).

Burt, T. L., Porretta, D. L., \& Klein, R. E. (2007). Use of adapted bicycles on the learning of conventional cycling by children with mental retardation. Education and Training in Developmental Disabilities, 42, 364-379.

Centers for Disease Control (2010). Overweight and obesity among people with disabilities. National Center on Birth Defects and Developmental Disabilities, Division of Human Development and Disability. Retrieved September 2, 2014 from http:// www.cdc.gov/ncbddd/disabilityandhealth/documents/obesityFactsheet2010.pdf

Clark, J. E., \& Metcalfe, J. S. (2002). The mountain of motor development: A metaphor. Motor Development: Research and Reviews, 2, 163-190.

Cohen, L., \& Manion, L. (1986). Research methods in education. London: Croom Helm.

Curtin, C., Anderson, S. E., Must, A., \& Bandini, L. (2010). The prevalence of obesity in children with autism: a secondary data analysis using nationaly representative data from the National Survey of Children's Health. BMC Pediatrics, 10, 1-5. DOI: 10.1186/1471-2431-10-11

Diener, C., \& Dweck, C. (1978). An analysis of learned helplessness. Continuous changes in performance, strategy, and achievement cognitions following failure. Journal of Personality and Social Psychology, 36, 451-462. DOI: 10.1037/0022-3514.36.5.451

Diener, C. \& Dweck, C. (1980). An analysis of learned helplessness: II. The processing of success. Journal of Personality and Social Psychology, 39, 940-952. DOI: 10.1037/0022-3514.39.5.940
Dwyer, T., Sallis, J. F., Blizzard, L., Lazarus, R., \& Dean, K. (2001). Relation of academic performance to physical activity and fitness in children. Pediatric Exercise Science, 13, 225-237.

Eichstaedt, C. B., Wang, P. Y., Polacek, J. J., \& Dohrmann, P. F. (1991). Physical fitness and motor skill levels of individuals with mental retardation: Mild, moderate, and Down syndrome, ages 6-21. Unpublished report. Illinois State University Printing Services, Normal, IL.

Esposito, P. E., MacDonald, M., Hornyak, J. E., \& Ulrich, D. A. (2012). Physical activity patterns of youth with Down Syndrome. Intellectual and Developmental Disabilities, 50, 109-119. DOI: org/10.1352/1934-9556-50.2.109

Fiske, B. (2005, December). Father of invention. Bicycling, 46, 33-35.

Fox, K. R. (1997). The physical self. Champaign, IL: Human Kinetics.

Fry, M., \& Duda, J. (1997). A developmental examination of children's understanding of effort and ability in physical and academic domains. Research Quarterly for Exercise and Sport, 68, 331-344. DOI: 10.1080/02701367.1997.10608014

Fujiura, G. T., Fitzsimons, N., Marks, B., \& Chicoine, B. (1997). Predictors of BMI among adults with Down syndrome: the social context of health promotion. Research in Developmental Disabilities, 18, 261-274. DOI: 10.1016/S0891-4222(97)00008-5

Goldstein, H., Kaczmerek, L. A., \& English, K. M. (2002). Promoting social communication: Children with developmental disabilities from birth to adolescence. Baltimore: Brookes Publishing.

Goodway, J. D., Wall, S. \& Getchell, N. (2009). Theory into practice: Promoting an "Active Start" for young children: Developing competent and confident early movers. Strategies: $A$ Journal for Physical and Sport Educators, 23, 30-32. DOI: 10.1080/08924562.2009. 10590865

Griffin, N. S. \& Keogh, J. F. (1982). A model for movement confidence. In: J. A. S. Kelso, \& J. E. Clark (eds.), The development of movement control and coordination (pp. 213-236). New York: Wiley.

Guralnick, M. J. (2000). Interdisciplinary team assessment for young children. In: M. J. Guralnick (ed.), Interdisciplinary clinical assessment of young children with developmental disabilities (pp. 3-15). Baltimore, MD: Paul H. Brookes.

Harter, S. (1987). The determinants and meditational role of global self-worth in children. In: N. Eisenberg (ed.), Contemporary topics in developmental psychology (pp. 219-242). New York: Wiley.

Harter, S. (1990). Causes, correlates, and the functional role of global self-worth: A life-span perspective. In: R. J. Sternberg, \& J. Kolligan (eds.), Competence considered (pp. 67-97). New Haven, CT: Yale University Press.

Hastings, R. P., Thomas, H., \& Delwiche, N. (2002). Grandparent support for families of children with 
Down's syndrome. Journal of Applied Research in Intellectual Disabilities, 15, 97-104.

Hauck, J., Jeong, I., Esposito, P., MacDonald, M., \& Ulrich, D. (2014). Benefits of bicycle riding in adolescents with autism and Down syndrome. Research Quarterly for Exercise and Sport, Supplement 85, A68.

Horn, T. S., \& Harris, A. (1996). Perceived competence in young athletes: Research findings and recommendations for coaches and parents. In: F. L. Smoll, \& R. E. Smith (eds.), Children and youth in sport: A biopsychosocial perspective (pp. 309-329). Madison, WI: Brown \& Benchmark.

Horovitz, M., \& Matson, J. L. (2012). Communication deficits in babies and infants with autism and pervasive developmental disorder-not otherwise specified (PDD-NOS). Developmental Neurorehabilitation, 13, 390-398.

Jobling, A. (1999). Attainment of motor proficiency in school-aged children with Down syndrome. Adapted Physical Activity Quarterly, 16, 344-361.

Jobling, A., \& Mon-Williams, M. (2000) Motor development in Down syndrome: a longitudinal perspective. In: D. J. Weeks, R. Chua, \& D. Elliott (eds.), Perceptual-motor behaviour in Down syndrome (pp. 225-248). Champaign, IL: Human Kinetics.

King, G., Law, M., Petrenchik, T., \& Hurley, P. (2013). Psychosocial determinants of out of school activity participation for children with and without physical disabilities. Physical \& Occupational Therapy in Pediatrics, 33, 384-404. DOI: 10.3109/01942638.2013.791915

Liberman, L., Ratzon, N., \& Bart, O. (2013). The profile of performance skills and emotional factors in the context of participation among young children with Developmental Coordination Disorder. Research in Developmental Disabilities, 34, 87-94. DOI: doi.org/10.1016/j.ridd.2012.07.019

Logan, W. S., \& Getchell, N. (2010). The relationship between motor skill proficiency and body mass index in children with and without dyslexia: a pilot study. Research Quarterly for Exercise and Sport, 81, 518-523.

Logan, S.W., Robinson, L. E.,Webster, E. K., Getchell, N., Liang, L., \& Golden, D. (2014). The relationship between motor competence and physical activity engagement during childhood: A systematic review. Research Quarterly for Exercise and Sport, Supplement 85, A14.

Logan, S. W., Scrabis-Fletcher, K., Modlesky, C., \& Getchell, N. (2011). The relationship between motor skill proficiency and body mass index in preschool children. Research Quarterly for Exercise and Sport, 82, 442-448.

Lotan, M., Henderson, C. M., \& Merrick, J. (2006). Physical activity for adolescents with intellectual disability. Minerva Pediatrica, 58, 219-226.

MacDonald, M., Esposito, P., Hauck, J., Jeong, I., \& Hornyak, J. (2012). Bicycle training for youth with Down syndrome and autism spectrum disorders. Focus on Autism and Other Developmental Disabilities, 27, 12-21.

MacDonald, M., Jaszewski, C., Esposito, P., \& UIrich, D. (2011). The effect of learning to ride a two-wheel-bicycle on the social development of children with autism spectrum disorder. Palaestra, 25, 37-42.

Mandler, J. M. (1992). How to build a baby: II. Conceptual primitives. Psychological Review, 99, 587-604.

Manjiviona, J., \& Prior, M. (1995). Comparison of Asperger syndrome and high-functioning autistic children on a test of motor impairment. Journal of Autism and Developmental Disorders, 25, 23-39.

Mari, M., Castiello, U., Marks, D., Marraffa, C., \& Prior, M. (2003). The reach-to-grasp movement in children with autism spectrum disorder. Philosophical Transactions of the Royal Society of London, Series B, Biological Sciences, 358, 393-403.

Matson, J. L., Dempsey, T., \& Fodstad, J. C. (2009). Stereotypes and repetitive/restrictive behaviours in infants with autism and pervasive developmental disorder. Developmental Neurorehabilitation, 12, 122-127. DOI: 10.1080/17518420902936730

Mayes, S. D., \& Calhoun, S. L. (2003). Ability profiles in children with autism: Influenced of age and IQ. Autism, 7, 65-80. DOI: 10.1177/1362361303007001006

McKiddie, B., \& Maynard, I. W. (1997). Perceived competence of school children in physical education. Journal of Teaching in Physical Education, 13, 324-339.

Menear, K. S. (2007). Parents' perceptions of health and physical activity needs of children with Down Syndrome. Down Syndrome Research and Practice, 12, 60-68. DOI: doi.org/10.3104/reports. 1996

Murphy, N. A., \& Carbone, P. S. (2008). Promoting the participation of children with disabilities in sports, recreation, and physical activities. $P e-$ diatrics, 121, 1057-1061. DOI: doi.org/10.1542/ peds.2008-0566

National Association for Sport and Physical Education (2004). Moving into the future: National standards for physical education ( $2^{\text {nd }}$ ed.). Reston, VA: American Alliance for Health, Physical Education, Recreation, and Dance.

Nicholls, J. (1978). The development of the concepts of effort and ability, perception of academic achievement, and the understanding that difficult tasks require more ability. Child Development, 55, 1990-1999.

O’Donoghue, T., \& Punch K. (2003). Qualitative educational research in action: Doing and reflecting. London: Routledge.

Parker, H. E., Monsoon, K. P., \& Larkin, D. (1993). Symmetrical and asymmetrical motor control in children: Bipedal and uni-pedal hopping. Human Movement Science, 12, 179-193. DOI: 10.1016/01679457(93)90042-N
Development of physical competence 
Kimberly Sue

Hurley,

Tammy Lee Burt
Payne, V. G., \& Issacs, L. D. (2008). Human motor development: A lifespan approach. New York: McGraw-Hill Companies, Inc.

Piek, J. P., Dawson, L., Smith, L. M., \& Gasson, N. (2008). The role of early fine and gross motor development on later motor and cognitive ability. Human Movement Science, 27, 668-681.

Pitchford, E. A., Hauck, J., Ketcheson, L., Reynolds, J., \& Ulrich, D. (2014). Use it or lose it: Bicycle riding maintenance in autism. Research Quarterly for Exercise and Sport, Supplement 85, A84.

Rimmer, J. H., \& Yamaki, K. (2006). Obesity and intellectual disability. Mental Retardation and Developmental Disabilities Research Reviews, 12, 22-27.

Sherrill, C. (2004). Adapted physical activity, recreation, and sport. New York: McGraw-Hill Companies, Inc.

Thelen, E., \& Ulrich, B. D. (1991). Hidden skills: A dynamic systems analysis of treadmill stepping during the first year. Monographs of the society for research in child development, 56 (1, Serial No. 223). Chicago, IL: University of Chicago Press.

Tsai, E., \& Fung, L. (2005). Perceived constraints of leisure time physical activity participation of students with hearing impairment. Therapeutic Recreation Journal, 39, 192-206.

Ulrich, D., Burghardt, A. R., Lloyd, M., Tiernan, C., \& Hornyak, J. E. (2011). Physical activity benefits of learning to ride a two-wheel bicycle for children with down syndrome: A randomized trial. Physical Therapy, 91, 1463-1477. DOI: 10.2522/ ptj.20110061

U.S. Congress. Senate and House of Representatives. Individuals with Disabilities Education Act, H.R. 1350. $108^{\text {th }}$ Congress $2^{\text {nd }}$ session 2004. Retrieved November 13, 2014 from http://www.nasponline. org/advocacy/ideacrsanalysis.pdf.

Virji-Babul, N., Eichman, A., \& Duffield, D. (2004). Development of a Canadian voluntary population based registry on Down syndrome: Preliminary results (2000-2002). Journal of Developmental Disabilities, 10, 113-122.

Vygotsky, L. S. (1978). Mind in Society: The development of higher psychological processes. Cambridge, MA: Harvard University Press.

Wade, M. G., Newell, K. M., \& Wallace, S. A. (1978). Decision time and movement time as a function of response complexity in retarded persons. American Journal of Mental Deficiency, 63, 135-144.

Webber, A., Virji-Babul, N., Edwards, R., \& Lesperance, M. (2004). Stiffness and postural stability in adults with Down syndrome. Experimental Brain Research, 155, 450-458.

Weiss, M. R., \& Ebbeck, V. (1996). Self-esteem and perceptions of competence in youth sport: Theory, research, and enhancement strategies. In: O. Bar-Or (ed.), The Encyclopaedia of sports medicine,
Volume VI: The child and adolescent athlete (pp. 364-382). Oxford: Blackwell Science Ltd.

Who we are. (n.d.-a). Retrieved November 27, 2014, from http://www.icanshine.org.

Who we are. (n.d.-b). Retrieved November 30, 2014, from http://www.rainbowtrainers.com. 